\title{
Usefulness of V-Y Advancement Flap for Defects after Skin Tumor Excision
}

\author{
Ki Hyun Kwon, Dong Gwan Lee, Su Han Koo, Myoung Soo Jo, Heakyeong Shin, \\ Jung Hyun Seul \\ Department of Plastic and Reconstructive Surgery, Dongguk University College of Medicine, Gyeongju, Korea
}

Background After skin tumor excision on the face, extremities, or trunk, the choice of treatment for a skin defect is highly variable. Many surgeons prefer to use a local flap rather than a skin graft or free flap for small- or moderately-sized circular defects. We have used unilateral or bilateral V-Y advancement flaps, especially on the face. Here we evaluated the functional and aesthetic results of this technique.

Methods All of the patients were pathologically diagnosed with squamous cell carcinoma (SCC), basal cell carcinoma (BCC), or malignant melanoma or premalignant lesion (Bowen's disease). Thirty-two patients underwent V-Y advancement flap repair (11 unilateral and 21 bilateral) from January 2007 to June 2011. We analyzed the patients' age and satisfaction, and location and size of defect. The patients were followed up for 6 months or more.

Results There were 22 women and 10 men. The ages ranged from 47 to 93 years with a mean age of 66 years. The causes were SCC in 15 cases, BCC in 13 cases, malignant melanoma in 1 case, Bowen's disease in 2 cases, and another cause in 1 case. The tumor locations were the face in 28 patients, and the scalp, upper limb, and flank each in one patient. All of the flaps survived and the aesthetic results were good. Postoperative recovery was usually rapid, and no complication or tumor recurrence was observed.

Conclusions The V-Y advancement flap is often used not only for facial circular defects but also for defects of the trunk and extremities. Its advantages are less scarring and superior aesthetic results as compared with other local flap methods, because of less scarification of adjacent tissue and because it is an easy surgical technique.

Keywords Surgical flaps / Skin neoplasms / Reconstructive surgical procedures
Correspondence: Jung Hyun Seul Department of Plastic and Reconstructive Surgery, Dongguk University College of Medicine, 87 Dongdae-ro, Gyeongju 780-350, Korea

Tel: +82-54-770-8242

Fax: +82-54-770-8501

E-mail: jhseul@med.yu.ac.kr

No potential conflict of interest relevant to this article was reported.

\section{INTRODUCTION}

The incidence of skin tumors is increasing in parallel with numbers of elderly patients. Furthermore, because skin tumors are asymptomatic, outpatient department visits are commonly delayed. Unsuccessful initial attempts to treat skin tumors medi- cally are also very common, which invariably means that tumor sizes are somewhat increased at presentation. Current treatment modalities for skin cancers and premalignant lesions include surgical excision, electrocautery, curettage, cryotherapy, and irradiation, but surgical excision has been reported to be the best treatment modality for cancer treatment and preventing recur-

Copyright $($ C 2012 The Korean Society of Plastic and Reconstructive Surgeons

This is an Open Access article distributed under the terms of the Creative Commons Attribution Non-Commercial License (http://creativecommons.org/

licenses/by-nc/3.0/) which permits unrestricted non-commercial use, distribution, and reproduction in any medium, provided the original work is properly cited.

www.e-aps.org 
rence. On the other hand, surgeons select the methods of reconstruction for the soft tissue defects after surgical excision based on considerations of the tumor type and location, patient age, and cosmetic and functional factors. There are four methods of reconstruction: primary closure, skin grafting, and local and free flaps.

Compared with skin grafts and free flaps, primary closure and local flap are advantageous because less scar tissue is formed following reconstruction, the use of similar adjacent tissue provides cosmetic benefits, and they do not have the risk of donor site morbidity. Thus, primary closure and local flap are frequently used, although primary closure is more advantageous than local flap because it is an easier surgical method and the scar has a linear shape. However, a wedge-shaped incision is needed for circular soft tissue defects, and thus, sacrificing normal tissue is unavoidable. Furthermore, because the scar is extended, primary closure is disadvantageous due to the excessive tension that is exerted in the areas where there is an insufficient amount of skin tissue.

Given the above background, to minimize the sacrifice of normal tissue and to avoid complications such as dog-ears or excessive tension, we used a unilateral or bilateral V-Y advancement flap to reconstruct the soft tissue defects following surgical excision of a skin tumor of the face, trunk, or extremities.

\section{METHODS}

Thirty-two patients underwent repair with a V-Y advancement flap between January of 2007 and June of 2011 at our institution. All of the patients had a circular tumor on the face, trunk, or extremity.

The unilateral V-Y advancement flap was used in 10 cases and the bilateral V-Y advancement flap in 22 cases. There were 22 women and 10 men, and their ages ranged from 47 to 93 years (mean, 66 years). The causes of soft tissue defects were excision of squamous cell carcinoma in 15 patients, basal cell carcinoma in 13 , and malignant melanoma in 1 patient. Additionally, 2 patients had a premalignant skin tumor due to Bowen's disease, and 1 patient had keratoacanthoma. The tumor diameters varied from 3 to $35 \mathrm{~mm}$ (mean, $16 \mathrm{~mm}$ ). Two patients were treated under general anesthesia and 30 under local anesthesia. In each case, after removing the skin tumor, it was given to a pathologist to confirm the absence of margin involvement. After hemostasis, repair was planned but it was not performed prior to receiving the pathologist's report (occasionally additional excision was necessary based on the results of the report). When the margins were declared clear, repair was planned. To increase flap survival, epinephrine was not injected in the excision margin. Almost all of the flap pedicles partially included subdermal plexus and fat tissue of the subcutaneous layer. After appropriate undermining, the flap was moved. We analyzed the patients' age, their satisfaction with the results, and the location and size of the tumors, and we also followed up with them for a mean of 6 months or more. We did not apply any algorithm to select a unilateral or bilateral V-Y advancement flap, and thus, the choice was made after considering the defect location, skin condition, and scarring.

\section{RESULTS}

Complete flap survival was achieved in all 32 cases. No flap necrosis, infection, dehiscence, hematoma, or seroma occurred. All of the patients had excellent skin coverage and no recurrence at the primary tumor site occurred during follow-up in any of the patients. Table 1 summarizes the patients' information.

\section{Case 1}

A 50-year-old patient presented with keratoacanthoma on the dorsal surface of the mid-right forearm. The diameter of the tumor was approximately $35 \mathrm{~mm}$, and it was resected along its margin. After excision, the skin defect was circular and about 40 $\mathrm{mm}$ in diameter. We were concerned that a substantial amount of normal adjacent tissue would be sacrificed to avoid a dog-ear defect and that the degree of tension would increase during primary closure using a wedge-shaped incision. Thus, a bilateral V-Y advancement flap was elevated, and this was followed by reconstruction of the skin defect. The flap survived without postoperative complications (Fig. 1).

\section{Case 2}

A 47-year-old man had basal cell carcinoma $1.5 \mathrm{~cm}$ in diameter of the left nasolabial fold, which was resected with a free margin of $0.5 \mathrm{~cm}$. The circular skin defect of approximately $2.5 \mathrm{~cm}$ in diameter was reconstructed using a unilateral V-Y advancement flap. In particular, the lower limb of the V flap was consistent with the relaxed skin tension line (RSTL). This procedure did not cause any undue deformity of the adjacent tissue, and good cosmetic results were obtained (Fig. 2).

\section{Case 3}

An 80-year-old patient had basal cell carcinoma of the nose tip. The tumor was $0.5 \mathrm{~cm}$ in diameter and was resected with a free margin of $0.5 \mathrm{~cm}$. The diameter of the soft tissue defect created was about $15 \mathrm{~mm}$, and the defect was repaired using a unilateral V-Y advancement flap. Postoperative recovery was rapid and the healing of the scars were satisfactory at the time of writing (Fig. 3). 
Table 1. Patient summary

\begin{tabular}{|c|c|c|c|c|c|}
\hline Patient & Sex/Age (yr) & Tumor location ${ }^{\text {a) }}$ & Method of flap & Period $^{\text {b) }}$ & Tumor type \\
\hline 1 & $F / 55$ & Eyelid & Bilateral & $10 \mathrm{yr}$ & Basal cell carcinoma \\
\hline 2 & $F / 68$ & Cheek & Bilateral & $1 \mathrm{yr}$ & Squamous cell carcinoma \\
\hline 3 & $F / 86$ & Cheek & Bilateral & $2 \mathrm{mo}$ & Squamous cell carcinoma \\
\hline 4 & $M / 66$ & Nose & Bilateral & $1 \mathrm{yr}$ & Basal cell carcinoma \\
\hline 5 & $\mathrm{~F} / 75$ & Chin & Bilateral & $5 \mathrm{mo}$ & Squamous cell carcinoma \\
\hline 6 & $\mathrm{~F} / 64$ & Nose & Bilateral & $7 \mathrm{yr}$ & Basal cell carcinoma \\
\hline 7 & $M / 82$ & Scalp & Bilateral & $2 \mathrm{yr}$ & Squamous cell carcinoma \\
\hline 8 & $\mathrm{M} / 47$ & Nasolabial fold & Unilateral & $2 \mathrm{yr}$ & Basal cell carcinoma \\
\hline 9 & $\mathrm{~F} / 74$ & Eyelid & Unilateral & $1 \mathrm{yr}$ & Basal cell carcinoma \\
\hline 10 & $\mathrm{~F} / 80$ & Cheek & Unilateral & $1 \mathrm{yr}$ & Basal cell carcinoma \\
\hline 11 & $\mathrm{M} / 72$ & Chin & Bilateral & $2 \mathrm{mo}$ & Squamous cell carcinoma \\
\hline 12 & $\mathrm{~F} / 83$ & Lip & Unilateral & $2 \mathrm{yr}$ & Squamous cell carcinoma \\
\hline 13 & $\mathrm{~F} / 67$ & Eyelid & Bilateral & $1 \mathrm{yr}$ & Basal cell carcinoma \\
\hline 14 & $\mathrm{~F} / 74$ & Eyelid & Unilateral & $1 \mathrm{yr}$ & Basal cell carcinoma \\
\hline 15 & $\mathrm{~F} / 84$ & Nose & Bilateral & $1 \mathrm{yr}$ & Squamous cell carcinoma \\
\hline 16 & $F / 55$ & Forehead & Bilateral & $1 \mathrm{yr}$ & Basal cell carcinoma \\
\hline 17 & $F / 81$ & Cheek & Bilateral & $3 \mathrm{mo}$ & Malignant melanoma \\
\hline 18 & $\mathrm{M} / 74$ & Lip & Bilateral & $3 \mathrm{mo}$ & Squamous cell carcinoma \\
\hline 19 & $F / 81$ & Eyelid & Unilateral & $3 \mathrm{mo}$ & Basal cell carcinoma \\
\hline 20 & $\mathrm{~F} / 87$ & Cheek & Unilateral & $1 \mathrm{yr}$ & Basal cell carcinoma \\
\hline 21 & $\mathrm{~F} / 72$ & Nose & Bilateral & $3 \mathrm{mo}$ & Squamous cell carcinoma \\
\hline 22 & $\mathrm{M} / 75$ & Chin & Bilateral & $8 \mathrm{yr}$ & Squamous cell carcinoma \\
\hline 23 & $\mathrm{~F} / 93$ & Chin & Unilateral & $3 \mathrm{yr}$ & Squamous cell carcinoma \\
\hline 24 & $\mathrm{M} / 80$ & Cheek & Bilateral & $5 \mathrm{yr}$ & Basal cell carcinoma \\
\hline 25 & $\mathrm{M} / 75$ & Lip & Unilateral & $3 \mathrm{mo}$ & Squamous cell carcinoma \\
\hline 26 & $\mathrm{~F} / 83$ & Lip & Unilateral & $3 \mathrm{mo}$ & Squamous cell carcinoma \\
\hline 27 & $\mathrm{~F} / 77$ & Cheek & Bilateral & $1 \mathrm{yr}$ & Squamous cell carcinoma \\
\hline 28 & $\mathrm{~F} / 50$ & Forearm & Bilateral & $3 \mathrm{yr}$ & Keratoacanthoma \\
\hline 29 & F/86 & Cheek & Bilateral & $1 \mathrm{yr}$ & Bowen's disease \\
\hline 30 & $\mathrm{~F} / 60$ & Trunk (right flank) & Bilateral & $2 \mathrm{yr}$ & Bowen's disease \\
\hline 31 & $M / 81$ & Cheek & Bilateral & $1 \mathrm{yr}$ & Squamous cell carcinoma \\
\hline 32 & $\mathrm{~F} / 80$ & Nose & Unilateral & $1 \mathrm{yr}$ & Basal cell carcinoma \\
\hline
\end{tabular}

\section{Case 4}

A 60-year-old patient had Bowen's disease on the right trunk. The diameter of the soft tissue defect was approximately $30 \mathrm{~mm}$, and a $3 \mathrm{~mm}$ free margin was obtained. The defect was repaired using a bilateral V-Y advancement flap. The patient complained of mild itching on the wound, but postoperative recovery was rapid and the scars were satisfactory at the time of writing (Fig. 4).

\section{DISCUSSION}

In our clinical series, the majority of the skin tumors were basal cell or squamous cell carcinomas, but there was one case of malignant melanoma. Precancerous lesions included Bowen's disease and keratoacanthoma. The diameters of the skin tumors varied from 3 to $35 \mathrm{~mm}$, and tended to be larger on the extremities and trunk than on the face, which probably reflects delay at presentation. The patients waited for more than 22 months on average to visit a hospital, and the tumor sizes obviously in- creased during this period. Additionally, patients tended to visit hospitals only when symptoms such as ulceration or bleeding developed, or when it was evident that a tumor was growing rapidly. Furthermore, because people tend to be more concerned about facial lesions, the patients with a facial lesion presented earlier. It should be added that our cohort was not drawn from an urban population, and thus, hospital accessibility undoubtedly affected this patient behavior.

Appropriate margins for malignant tumors depend on the cancer type, tumor size, tumor irregularity, and time elapsed from onset. In cases of basal cell carcinoma, an appropriate excision margin would be 2 to $5 \mathrm{~mm}$ from the tumor, whereas in cases with a small-sized lesion of $<2 \mathrm{~cm}$ in diameter, it would be approximately $4 \mathrm{~mm}$. On the other hand, in cases with a lesion of $>2 \mathrm{~cm}$ in diameter or with a substantial delay after onset, the margin would be $1 \mathrm{~cm}$, and in recurrent cases, it would be $>1$ $\mathrm{cm}$. Squamous cell carcinoma has a more invasive growth pattern than basal cell carcinoma, and in untreated cases a margin of 

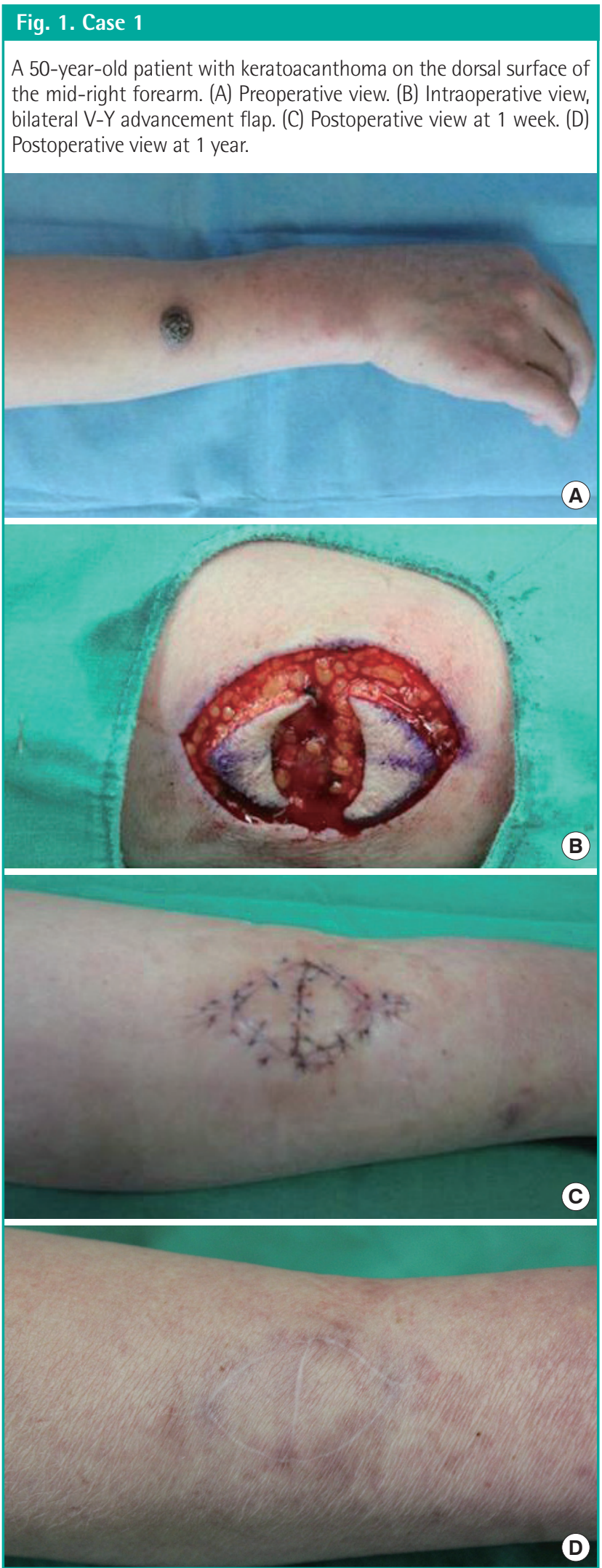

excision of $>1 \mathrm{~cm}$ is required. In patients with a longer disease history, a margin of 2 to $3 \mathrm{~cm}$ is required [1,2]. Furthermore, in cases of malignant melanoma, a treatment plan should be pre-

\section{Fig. 2. Case 2}

A 47-year-old man with squamous cell carcinoma of $1.5 \mathrm{~cm}$ in diameter on the right nasolabial fold. (A) Preoperative view. (B) Intraoperative view. (C) Postoperative view at 3 months.
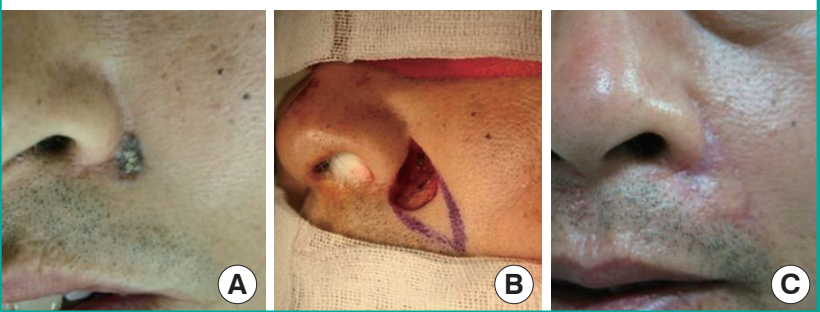

\section{Fig. 3. Case 3}

(A) Preoperative view. $(B, C)$ Intraoperative view, unilateral $V-Y$ advancement flap. (D) Postoperative view at 15 months.
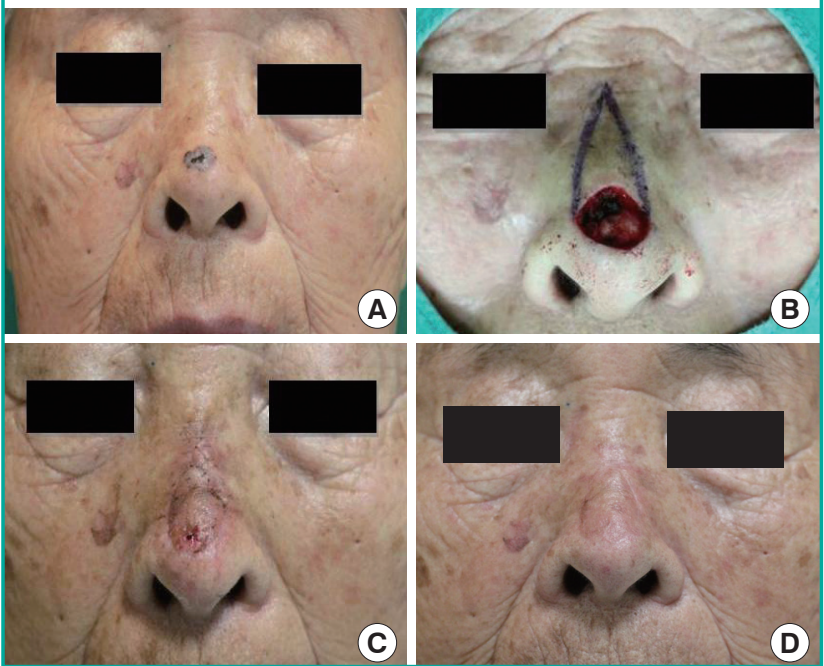

pared after a meticulous examination for metastasis is conducted in adjacent tissues, organs, and lymph nodes. In the absence of any evidence of metastasis, the margin of excision should be 2.5 to $5 \mathrm{~cm}$ and extensive resection should be performed. Additionally, recurrence should be monitored with regular follow-up. In an attempt to minimize recurrence, we performed wide excision. Furthermore, we used a free margin of 3 to $5 \mathrm{~mm}$ in cases of basal cell carcinoma, $1 \mathrm{~cm}$ in cases of squamous cell carcinoma, and $2.5 \mathrm{~cm}$ in cases of malignant melanoma.

In the present study, the arbitrary definitions used to describe the sizes of skin defects were 'small' ( $<15 \mathrm{~mm}$ ), 'medium' ( 15 to $30 \mathrm{~mm}$ ), or 'large' ( $>30 \mathrm{~mm}$ ). The majority of the patients had a small-to-medium defect, but five cases had a large defect.

Four methods are used to reconstruct soft tissue defects after the surgical excision of skin tumors: primary closure, skin graft, and local and free flaps. The most important factors to be considered for reconstruction are defect location and shape. In this article, we addressed only circular defects. 


\section{Fig. 4. Case 4}

(A) Preoperative view. (B) The diameter of the soft tissue defect was approximately $30 \mathrm{~mm}$. The defect was repaired using a bilateral V-Y advancement flap. (C) Postoperative view at 1-month. (D) Postoperative view at 15 months.
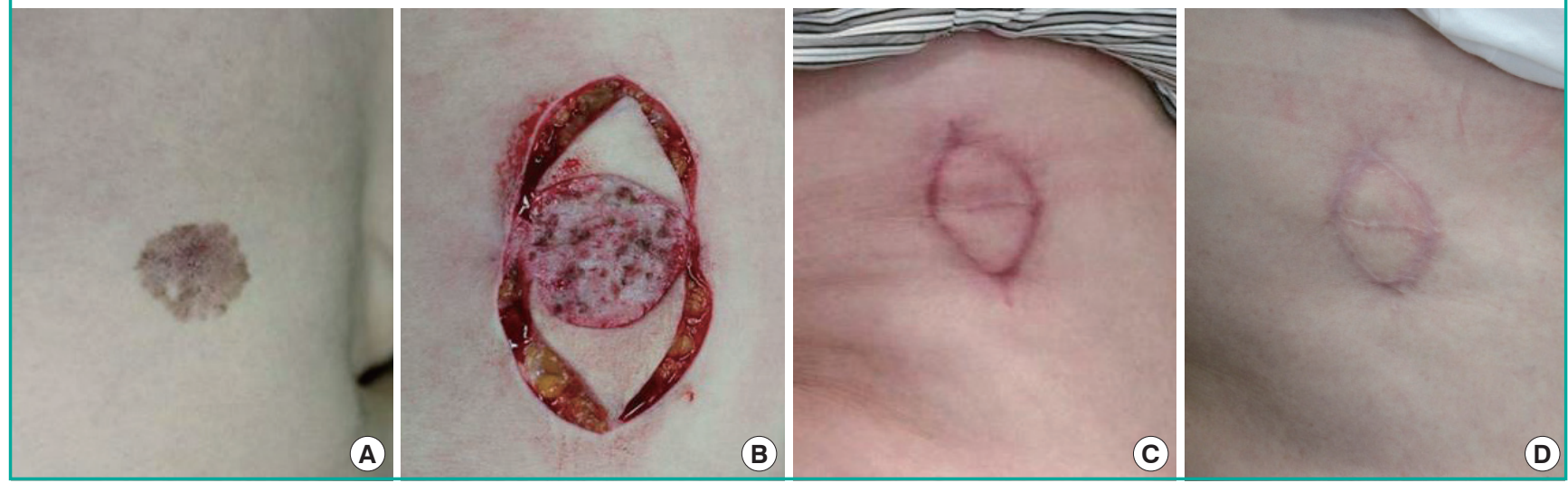

Primary closure is the most commonly used method to treat soft tissue defects. In the reconstruction of primary closure for circular defects, a dog-ear had been considered the standard approach. To avoid dog-ears, an elliptical excision would be needed that would include adjacent normal tissue. As a result, it would create a longer scar than the defect. Therefore, primary closure may not be appropriate for use in the facial region from a cosmetic perspective. Furthermore, regarding skin defects of the trunk or extremities that are close to a joint, much tension is present, and thus, in some cases primary closure might interfere with joint mobility.

Skin grafting is usually performed when defects are large and unsuitable for primary closure or a local flap. However, skin grafts are less desirable due to the color differences between the donor and recipient sites and scarring. Therefore, in patients with smallto-medium defects, a local flap rather than a skin graft is preferred. Various local flap methods can be used, the application of which are dependent on skin tissue status and skin defect location [3]. In practice, the optimal method for a local flap depends initially on the surgeon's preference. Rotational flaps are used frequently, but although the procedure is straightforward, it has the disadvantages of leaving large elliptical scars, requiring the resection of a large amount of normal skin tissue, and causing anatomical deformities of the adjacent structures. In particular, in younger patients, rotational flaps exert excessive tension on the face, where there is no redundant skin, and leave obvious scars. A Limberg flap, mainly used for rhomboid skin defects, is a method where a quadrangular flap with four sides of the same length is transferred; the flap is designed to ensure that there are no differences in the lengths of the two sides and two angles that face each other. However, skin defects should have a circular or an elliptical shape following skin tumor excision, and to make them rhomboidal, much normal skin tissue must be sacrificed, which would cause significant deformity in the facial region. Thus, indications for the Limberg flap are somewhat limited [4]. The bilobed flap utilizes two flaps to restore skin defects. However, because maximum coverage is less than $2 \mathrm{~cm}$, the flap cannot be used frequently; and it can also cause trapdoor deformity [4].

Thus, we use V-Y advancement flaps with a unilateral or bilateral pedicle to reconstruct soft tissue defects after the surgical excision of skin tumors of the face, body trunk, or extremities. This method involves the transfer of a V-shaped flap to the defect site and converting it to a Y-shaped flap using a random pattern flap involving dermal plexus and subdermal plexus, which are connected by a subcutaneous perforating artery arising from the muscle [5] (Fig. 5). The subcutaneous pedicled V-Y flap has been previously described by many authors including $\mathrm{Du}$ fourmentel and Talaat [6] who have coined the term "kite flap", which also refers to cases in which the skin island overlies the orbicularis oculi muscle for defects of the medial canthus and lower lid. The flap is optimally designed so that the common limb of the $Y$ falls into the boundary with neighboring aesthetic regions or within a natural crease, fold, or wrinkle.

The V-Y advancement flap is particularly useful when a structure or region requires lengthening or release from a contracted state. Less scar tissue, such as trap-door deformity, is formed when this flap is used than when the conventional transposition flap is used in cases involving the alar crease, nasolabial fold, or malar crescent $[6,7]$. When a skin tumor is present on the margin of an aesthetic unit, excellent cosmetic outcomes can be obtained using a V-Y advancement flap. In particular, a bilateral V-Y advancement flap is advantageous for placing the skin defect on the RSTL, which is achieved by adjusting the length of the two 


\section{Fig. 5. V-Y advancement flap}

(A) Basic design of a bipedicled V-Y advancement flap, and postoperative stigmata. (B) Components of the flap. The flap paddle includes the dermal plexus and subdermal plexus from the perforating artery.
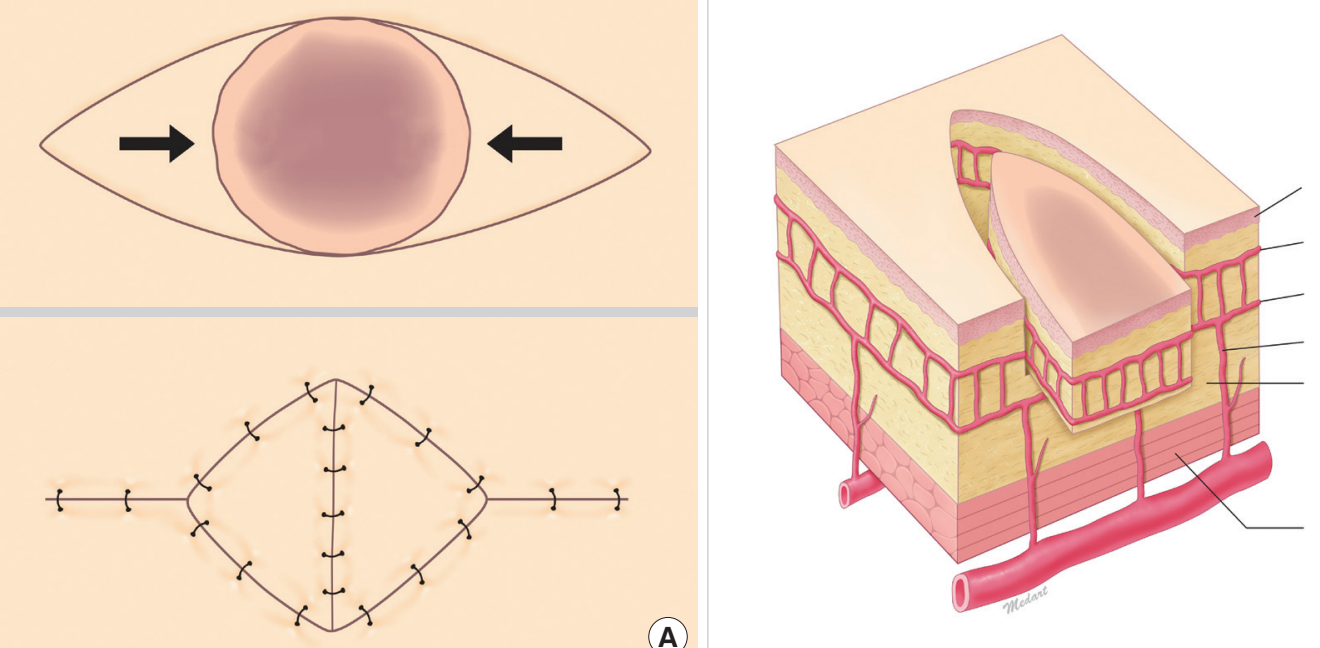

Epidermis

Dermal plexus

Subdemal plexus

Perforating artery

Subcutaneous and fat tissue

(A)

pedicles. In elderly patients, by identifying redundant skin areas, we have transferred bilateral flaps after adjustment for size. Thus, by using V-Y advancement flaps we have achieved excellent cosmetic outcomes in the facial region.

Scar widening is related to ongoing tension. According to geometric analysis, compared with a pivot flap that includes a rotational flap and transpositional flap, the V-Y advancement flap provides much less tension, which reduces the risk of hypertrophic changes and scar widening in the long term [8].

In the trunk and extremities, the V-Y advancement flap is disadvantageous because it leaves rhomboidal scars. Nevertheless, a bilateral V-Y flap can be particularly useful for the treatment of large circular or elliptical skin defects of $>30 \mathrm{~mm}$ in diameter. Primary closure is commonly performed for the trunk and extremities. However, because primary closure requires a wedge-incision, it exerts excessive tension on joint areas, which might lead to complications such as wound dehiscence, as well as requiring sacrifice of normal adjacent tissue. On the other hand, the V-Y flap has a smaller degree of displacement; therefore; it causes less tension, and thus, fewer complications such as wound dehiscence. Furthermore, because a V-Y flap also creates a smaller dead space, it presents lower risks of postoperative complications such as seroma and hematoma. Many surgeons tend to be wary of the stigmata of the V-Y advancement flap especially on the trunk and extremity, which are less wrinkled and creased than the face. However, we are of the opinion that that the size of the stigmata is similar to that of the defect, and we explain this to patients beforehand.
Another disadvantage is scar revision for stigmata of a V-Y advancement flap. Although abnormal scar formation, such as a hypertrophic scar or widening scar, occurs less often with V-Y flaps than with the other flap methods, the stigmata is not linear; it is of a rhomboidal shape. Therefore, it is very difficult to correct the scar by making it invisible.

Although there are various methods for reconstructing skin defects created by skin tumor resection, we believe that the V-Y advancement flap produces good treatment outcomes in cases with small-to-medium defects. Furthermore, the use of the unilateral or bilateral V-Y advancement flap can be extended not only for facial circular defect but also on the trunk and extremities. The advantages of this local flap over other local flaps are less scarring and superior aesthetic results, which are due to less scarification of adjacent normal tissues and because it is a straightforward surgical procedure.

\section{REFERENCES}

1. Mark AS. Nonmelanoma skin cancer. Clin Plast Surg 1997; 24:681-95.

2. Thomas DJ, King AR, Peat BG. Excision margins for nonmelanotic skin cancer. Plast Reconstr Surg 2003;112:57-63.

3. Suh CD, Kim SK, Kim SS. Local flaps in facial reconstruction. J Korean Soc Plast Reconstr Surg 1987;14:417-29.

4. Baker SR, Swanson NA. Local flaps in facial reconstruction. St. Louis: Mosby; 1995.

5. Zook EG, Van Beek AL, Russell RC, et al. V-Y advancement 
flap for facial defects. Plast Reconstr Surg 1980;65:786-97.

6. Dufourmentel C, Talaat SM. The kite flap. In: Hueston JT. Transactions of the Fifth International Congress of Plastic and Reconstructive Surgery, Melbourne, 22-26 February 1971. Melbourne: Butterworths; 1971. p. 1123-4.

7. Kalus R, Zamora S. Aesthetic considerations in facial recon- structive surgery: the V-Y flap revisited. Aesthetic Plast Surg 1996;20:83-6.

8. Andrades PR, Calderon W, Leniz P, et al. Geometric analysis of the V-Y advancement flap and its clinical applications. Plast Reconstr Surg 2005;115:1582-90. 